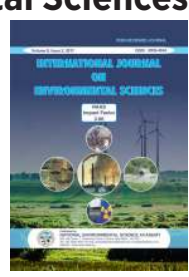

\title{
GLOBAL RESPIRATORY ILLNESS OUTBREAK COVID-19 AND ITS GLOBAL CONSEQUENCES: AN OVERVIEW
}

\author{
Chetan Chauhan ${ }^{1}$ and Shanta Kumari ${ }^{2}$ \\ ${ }^{1}$ Division Chemistry, University Institute of Sciences \\ Chandigarh University, Gharuan, Distt. Mohali, Punjab, INDIA \\ ${ }^{2}$ Department of Economics, Eternal University, Baru Sahib, Distt.Sirmour, H.P
}

Research Article

Received: 20.10.2020

Revised: 05.11.2020

Accepted: 15.11.2020

\section{ABSTRACT}

Global Respiratory illness outbreak COVID-19 is a new public health crisis threatening humanity across the globe with the emergence and spread from central China in late 2019. The virus originated around Wuhan, Hubei province, China in December 2019 in bats and was transmitted through unknown intermediary sources to humans. The clinical presentation of viral infection ranges from asymptomatic to severe pneumonia with acute pulmonary distress syndrome is designated as COVID-19. WHO has characterized the disease as a pandemic due to its severity, as well as the shifting of epidemic zones across the globe from epicentre zone, China through a different stage of transmission by contact or inhalation with infected droplets and the incubation period, varies between 2 - 14 days. Treatment is essentially supportive; the effective role of antiviral agents is yet to be established and secondly without knowing the entire genome sequence of COVID-19, no drug or vaccine can be effectively administered. Prevention entails home isolation of suspected cases and those with mild illnesses and strict infection control measures at hospitals that include contact and droplet precautions. The highest risk of healthcare-associated transmission is in the absence of standard precautions, when basic infection prevention and control measures for respiratory infections are not in place, and when handling patients where COVID infection is yet to be confirmed. The pandemic acceleration of COVID-19 indicates that the initial sporadic spreading worst hit the epicentre, China. But later on, epidemic zone shifts to nearly all continents. Several countries are experiencing sustained local transmission, including Europe and America at the end of February 2020. Current status indicates that confirmed and death cases pattern is rapidly varied among the different continents and emerged as an alarming health crisis of the Era in countries like Italy, Spain, U.K, Iran, and the USA. Although India is now in the $2^{\text {nd }}$ stage of transmission and too far from the $3^{\text {rd }}$ stage but till government has already taken deceive control measures. At the same time some of the Asian countries like South Korea, Japan has been reporting a slowdown in the growth of COVID-19 cases due to adoption concept of "Testing is central" to outbreak response that leads to early detection to minimizes further spread. The proportion of asymptomatic cases is currently unknown and hampers the realistic assessment of the virus epidemic potential and complicates the outbreak response. WHO has already announced a large global trial, called SOLIDARITY on $27^{\text {th }}$ March 2020 which is focusing on the most promising panacea therapies including remdesivir; chloroquine and hydroxychloroquine; a combination of two HIV drugs, lopinavir, and ritonavir; and that same combination plus interferon-beta. The coronavirus (COVID-19) outbreak has already brought considerable human suffering and major economic disruption. In the current scenario, the exact global impact and extension of COVID 19 pandemic acceleration and reoccurrences of $2^{\text {nd }}$ and $3^{\text {rd }}$ waves are yet uncertain in globally. Therefore the corona pandemic is unprecedented in its global impact and reach, posing alarming challenges to policymakers, researchers and health workers.

Keywords: COVID-19, CoVs, WHO, personal protective equipment (PPE) and pandemic.

\section{INTRODUCTION}

Unknown aetiology cases of pneumonia like disease were reported in Wuhan, Hubei Province, Central China on 31
December 2019. The Pathogenic agent was identified as a novel coronavirus-19 (COVID-19) which has since then infected millions and killed thousands of people. The term

*Corresponding author: chauhan.chetan123@gmail.com 
"coronavirus," coined in 1968, is imitative from the "corona"-like or crown-like morphology observed for these viruses in the electron microscope [1]. In 1975, the Coronaviridae family was established by the International Committee on the Taxonomy of Viruses. Coronaviruses (CoVs) include a group of positivestranded RNA enveloped viruses that infect a wide range of animal hosts including humans. CoVID -19 is retrovirus where the RNA undergoes reverse transcription, forming the complementary DNA (cDNA) by the enzyme reverse transcriptase. This enzyme will convert the RNA of the coronavirus to cDNA and which later on inserted into the host DNA, replicating along with the host DNA and causing lysis of the host cell after reaching its burst size, generating a greater number of virions/virus particles, causing reinfection of the same organism or other organisms. In this way, the progeny virions have multiplied to such an extent that despite their minute size they can outnumber their host cells and rule over them by causing infection. The emerging viral particles can reinfect its neighboring hosts and spread in the community[2,3,4]. Besides respiratory and enteric infection such viruses can cause in a hepatic, renal and neuronal disorders many species of animals, including humans. The clinical presentation of viral infection ranges from asymptomatic to severe pneumonia with acute pulmonary distress syndrome, septic shock, and multi-organ failure. Reported illnesses have ranged from mild symptoms to severe illness and death. These symptoms may appear 2-14 days after exposure based on the incubation period of novel coronavirus viruses. Emergency warning signs of COVID-19 include trouble breathing persistent pain or pressure in the chest, new confusion or inability to arouse and bluish lips or face [5].

\section{The sporadic distribution of pandemic COVID-19 across the globe}

\section{Current global status of COVID-19}

In December 2019, a novel coronavirus, designated as SARS-CoV-2, has caused an international respiratory illness outbreak termed as COVID-19 around the globe. WHO (on $11^{\text {th }}$ March 2011) made the assessment and characterized the COVID-19 disease as a pandemic due to its severity as well as shifting epidemic zones across the globe from epicentre zone of China through different stages of transmission till date (Figure 1). Recent WHO reports confirmed that there have been more 5,71,678 reported cases of COVID-19 and 26494 confirmed deaths worldwide which disrupted the lives of millions. Few regions/zones of the globe are left out of this crisis but trends suggest that such zone may be penetrated by COVID - 19 in the coming time. But current estimates of COVID-19's case-fatality rate suggest that the coronavirus is less

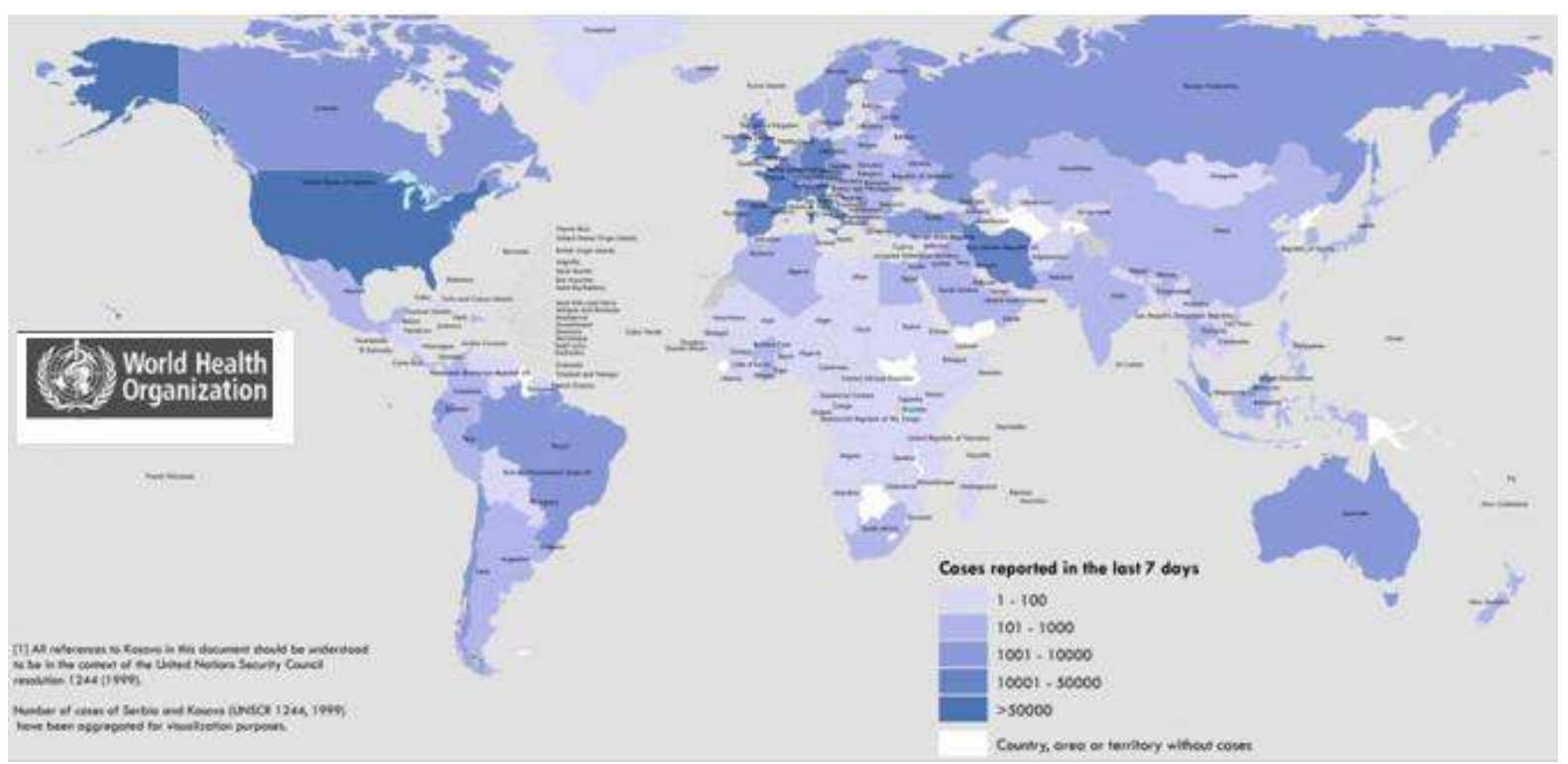

Fig.1: Worldwide (countries, territories or area) status of reported confirmed COVID-19 cases, 28 March 2020 [Source WHO, situation Report 28, March 2020]. 
deadly than the pathogens behind other large-scale outbreaks, such as severe acute respiratory syndrome, Middle East respiratory syndrome and Ebola. But the infection also seems to spread more easily than other diseases, including seasonal influenza as shown in Figure 2. As per Nature publication, the calculations of the virus's basic reproduction number or $\mathrm{R}_{0}$ (the number of people on an average one infected person will pass the virus to) suggest a range of $2-2.5$ as in case of China and during the early stage of an outbreak on a cruise ship

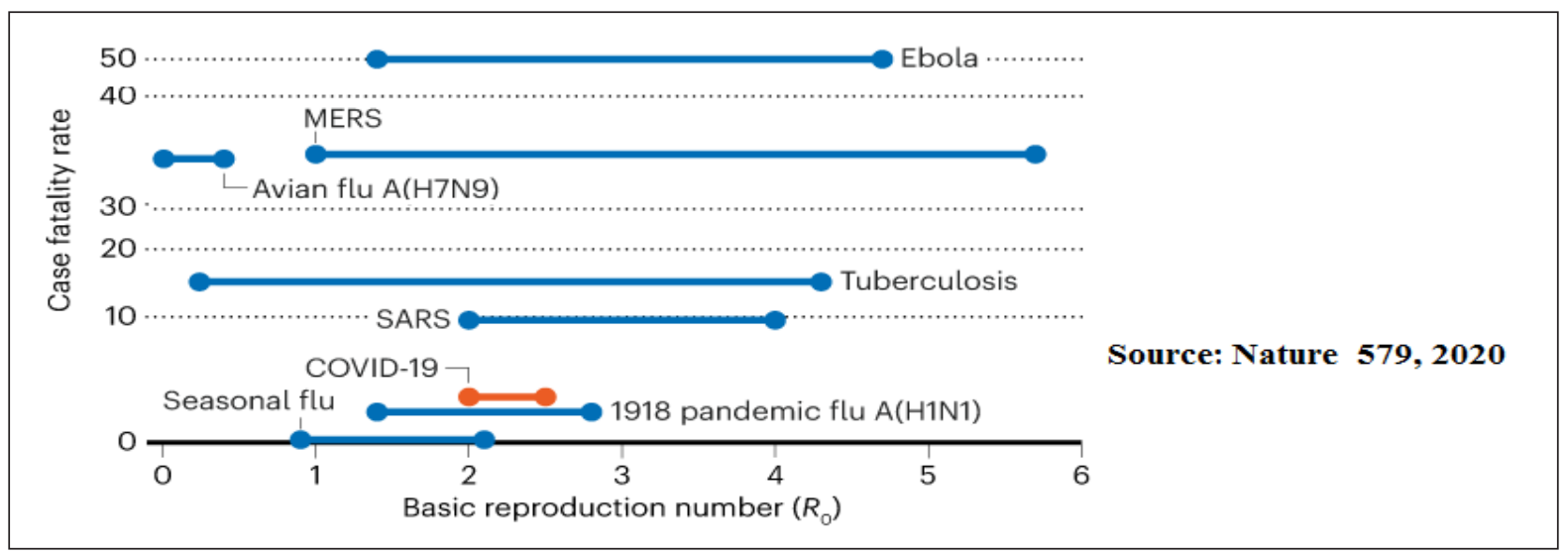

Figure 2: Comparison of COVID-14 Vs Other Diseases in term of fatality rate.

Throughout the infection, the virus has been identified in respiratory tract specimens 1-2 days before the onset of symptoms and it can persist for 7-12 days in moderate cases and up to 2 weeks in severe cases. The COVID-19 has been detected in asymptomatic persons. In the case of a sea ship outbreak, where most of the members were tested irrespective of symptoms, the laboratory-confirmed $51 \%$ cases were asymptomatic at the time of confirmation $[5,6]$. Vulnerable population includes those having severe disease and death cases includes personals having age above 60 years, males, with underlying conditions like as diabetes, chronic respiratory disease etc [7]. Although both SARS and COVID-19 emerged in china authorities have been comparative faster to respond to the latest outbreak (Figure 3). But China had notified the WHO of a spike in cases of a pneumonia-like disease, three weeks after the first known case of the disease now known as COVID19[8].

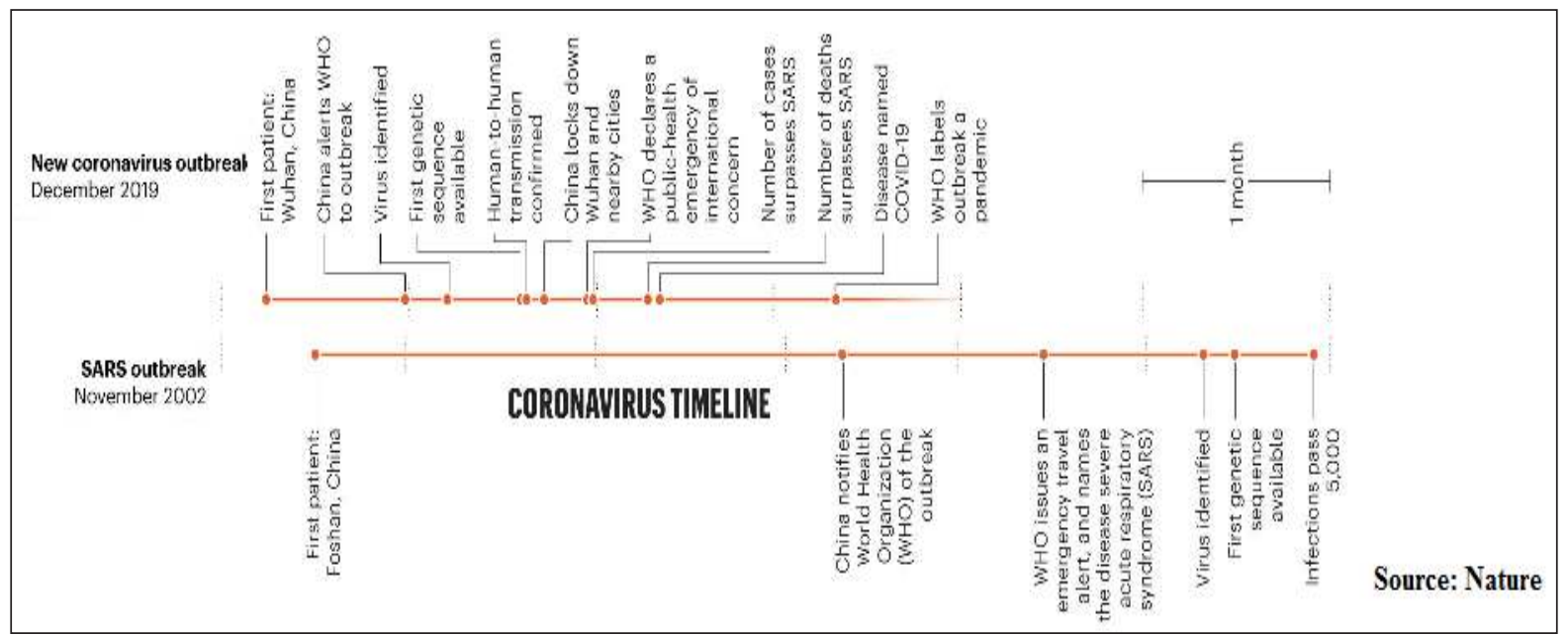

Figure 3: Comparative coronavirus timeline of SARS and COVID-19. 


\section{Transmission mode}

As CoVs generally spread either through respiratory route or fecal-oral or epithelial cells represent their first natural barrier. Hence, their interface interaction with such cells determines the outcome of the infection [8]. In most cases the COVID -19 transmitted either through inhalation or mucosal surfaces deposition of large respiratory droplets from person-to-person contact. Other routes have also been implicated in the transmission of coronaviruses, such as contact with contaminated fomites and inhalation of aerosols. In absence of standard precautions, the highest risk of healthcare-associated transmission is plausible, when main infection prevention and control measures for pulmonary infections are not in place, and when treatment patients where COVID-19 infection is yet to be established. Although there is so far no data of airborne transmission, we recommend a observant approach due to a lack of studies exclusive of this mode of transmission [9].

\section{Transmission Stages}

Infectious diseases like COVID -19, diseases can be spread, directly or indirectly, from one person to another by the following stages of transmission.

i. The first stage of transmission: The first stage appears when cases of infection are imported into a country which was not the source of the infection. In COVID -19 case, all the countries outside of China which started reporting cases of coronavirus reached
Stage 1 of the outbreak as soon as they reported their first case.

ii. The second stage of Transmission: If an outbreak is when there are cases of local transmission in the country, the reported transmission is $2^{\text {nd }}$ stage transmission. This means that the person from whom the infection spread to another person is from the country itself. In this stage, the trajectory of the virus can be identified from the source to all the infected individuals.

iii. The third stage of Transmission: Community transmission is the third stage of an outbreak. In this stage, it becomes hard to track the chain of transmission of the virus in a large number of cases. This means that the virus has started circulating within the community and can also infect those individuals who have neither travelled to a country affected by the outbreak nor have come into the contact of a person infected by the virus. In this case, a lockdown becomes highly important as any person can spread the virus, regardless of their travel history or people they have come in contact with. iv. The fourth stage of transmission: This occurs when an infection becomes endemic in some countries and keeps resurfacing round the year, like malaria and dengue in India.

The transmission classification in major COVID affecting countries (Table 1) seems to varies from time of origin.

Table 1: Mode of transmission around the globe in current scenario [WHO, situation report, Nov, 2020].

\begin{tabular}{|l|l|l|l|l|}
\hline S. No & Country & $\begin{array}{l}\text { Confirmed cases - } \\
\text { cumulative total }\end{array}$ & $\begin{array}{l}\text { Confirmed Deaths - } \\
\text { cumulative total }\end{array}$ & Transmission Classification \\
\hline 1 & USA & $9,193,765$ & 229,948 & Community transmission \\
\hline 2 & India & $8,313,876$ & 123,611 & Clusters of cases \\
\hline 3 & Brazil & $5,554,206$ & 160,253 & Community transmission \\
\hline 4 & Russia & $1,673,686$ & 28,828 & Clusters of cases \\
\hline 5 & France & $1,433,254$ & 37,115 & Community transmission \\
\hline 6 & Spain & $1,185,678$ & 35,878 & Community transmission \\
\hline 7 & Argentina & $1,183,131$ & 31,623 & Community transmission \\
\hline 8 & Colombia & $1,093,256$ & 31,670 & Community transmission \\
\hline 9 & U.K & $1,053,868$ & 46,853 & Community transmission \\
\hline 10 & Mexico & 933,155 & 92,100 & Community transmission \\
\hline 11 & Italy & 731,588 & 39,059 & Clusters of cases \\
\hline 12 & South Africa & 727,595 & 19,465 & Community transmission \\
\hline
\end{tabular}




\begin{tabular}{|l|l|l|l|l|}
\hline 13 & Iran & 637,712 & 36,160 & Community transmission \\
\hline 14 & Germany & 560,379 & 10,661 & Clusters of cases \\
\hline 15 & Chile & 514,202 & 14,319 & Community transmission \\
\hline 16 & Iraq & 482,296 & 11,068 & Community transmission \\
\hline 17 & Belgium & 447,260 & 11,858 & Community transmission \\
\hline 18 & Indonesia & 418,375 & 14,146 & Community transmission \\
\hline 19 & China & 92,045 & 4,746 & Clusters of cases \\
\hline
\end{tabular}

Pandemic acceleration patterns since its outbreak The pandemic acceleration of COVID-19 indicates that initial sporadic distribution worst-hit China. But later on, epidemic zone shifts to nearly all continents. Several countries are experiencing sustained local transmission, including in Europe by the end of February 2020. Current status indicates that confirmed and death cases pattern is rapidly varied among the different continents. But the present situation emerged as an alarming health crisis of the Era in countries like
Italy, Spain and U.K, Iran and the USA, etc. WHO reports confirmed that there have been more 324,343 confirmed cases of COVID-19 and 18740 confirmed deaths in European countries; 100317 confirmed cases of COVID-19 and 1483 confirmed deaths in American countries till $28^{\text {th }}$ March 2020. Basic pattern during going health crisis across the globe can be emerged by cases reported daily as shown in the epidemic curve since its outbreak (Figure 4)

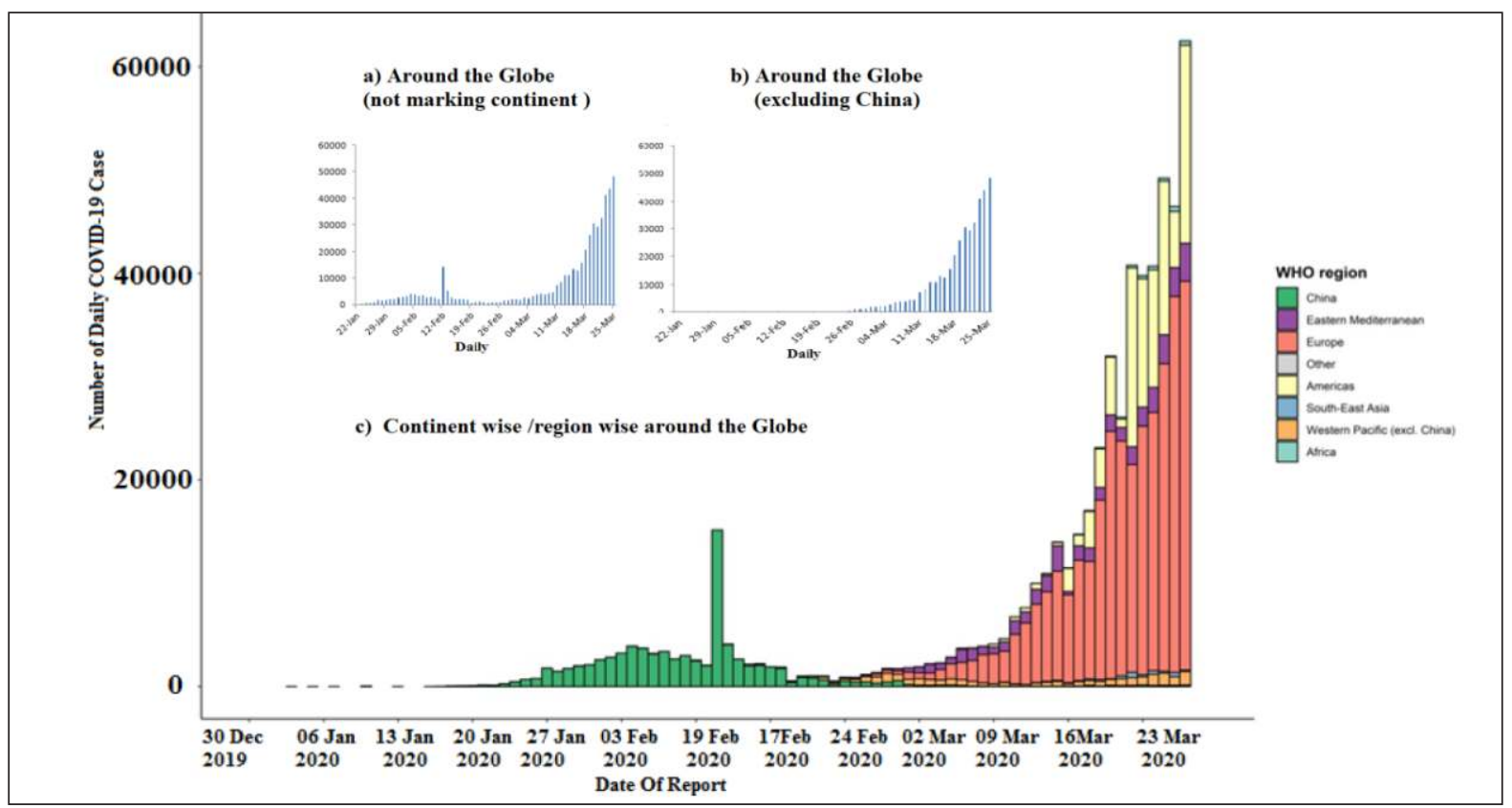

Figure 4: Epidemic Curve of confirmed COVID-19 by date of report [Source WHO, situation Report 28, March 2020].

WHO warned "the pandemic is accelerating" with it taking 67 days for cases to reach the 100,000 marks globally 11 days for cases to reach 200,000 and just four days cases to reach 300,000 . Now after the outbreak of CVID-19, China has nearly maintained and contained at $17.22 \%$ the total COVID-19 cases but still, there is concern over recovered cases (Figure4). Johns Hopkins University prediction suggested that the US (late March, 2020) has more suspected and confirmed cases of Covid-19 than China (82,404 reported in the US and 81,782 in China. Italy is third with 80,589). 


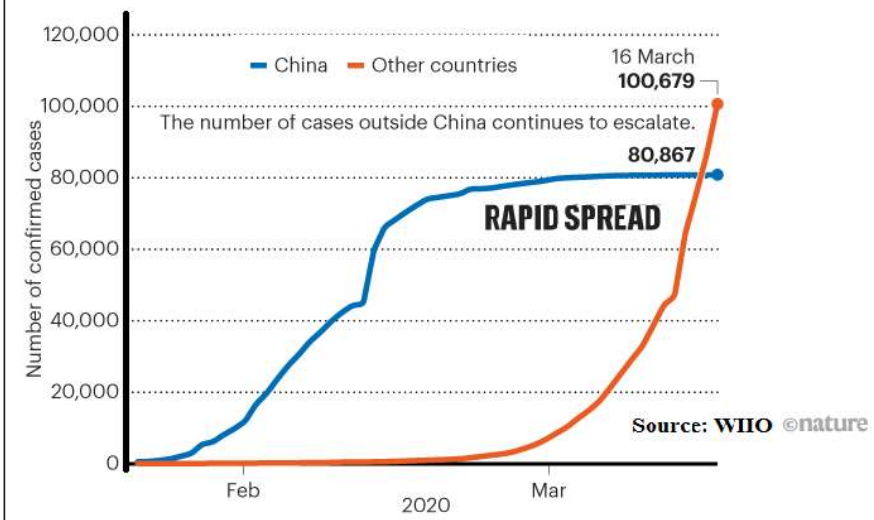

a) China maintan/Contain Vs Global pandamic Acceleration of COVID-19

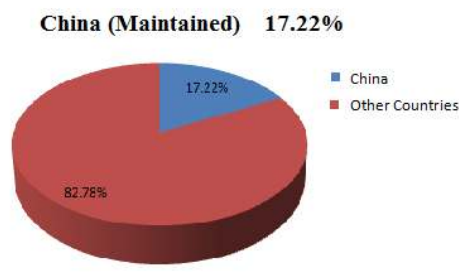

Source: Worldometer - $\underline{\text { www.worldometers.info }}$

b) \%age distribution of COVID cases w.r.t China

Figure 5: Comparison of pandemic acceleration and \%age wise with Chin $\left[16^{\text {th }}\right.$ March 2020$]$.

In some Asian countries like Japan and South Korea has been reporting a slowdown in the growth of COVID-19 cases (Figure 6). South Korea contains the cases without some of the harsh lockdown strategies deployed elsewhere across the globe. Because the South Korean developed testing capacity in the country for the virus even before it had a significant confirmed case of COVID-19 and adopt the concept "Testing is central" to outbreak response that leads to early detection to minimizes further spread and allows health authorities to quickly isolate for treatment.
Despite such slowdown recently it had a significant number of cases several places have seen surges in imported cases from Europe. Although a trend across the globe is a matter of concern and seems to be increasing in term of confirmed/ death cases and sporadic distribution area.

In the current situation more than 47,059,867 confirmed cases and 1,207,327 deaths reported by WHO as shown below in Figure 7.

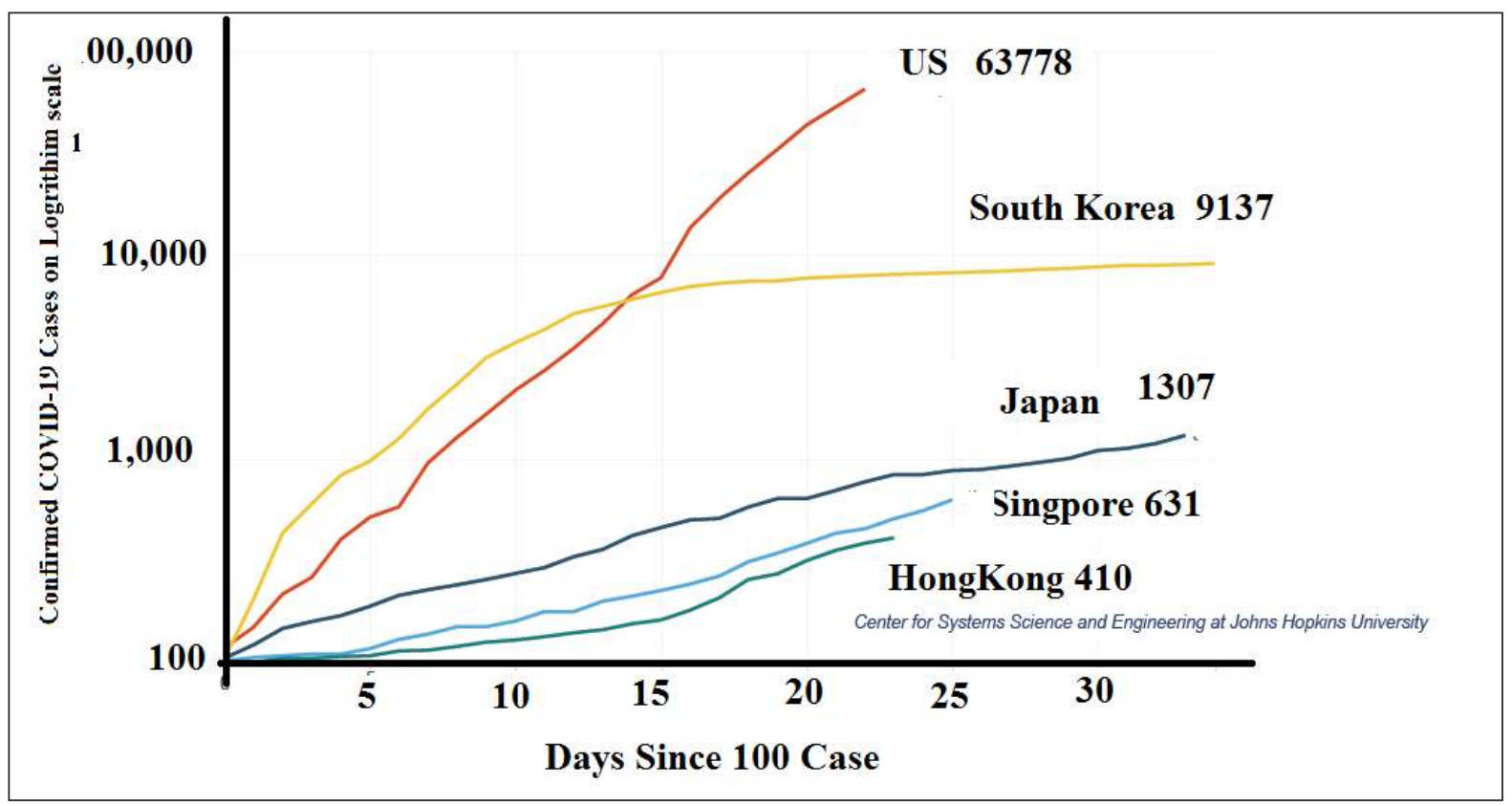

Figure 6: Slowing outbreaks in several Asian countries plotted on the logarithmic scale after the 100th case. 


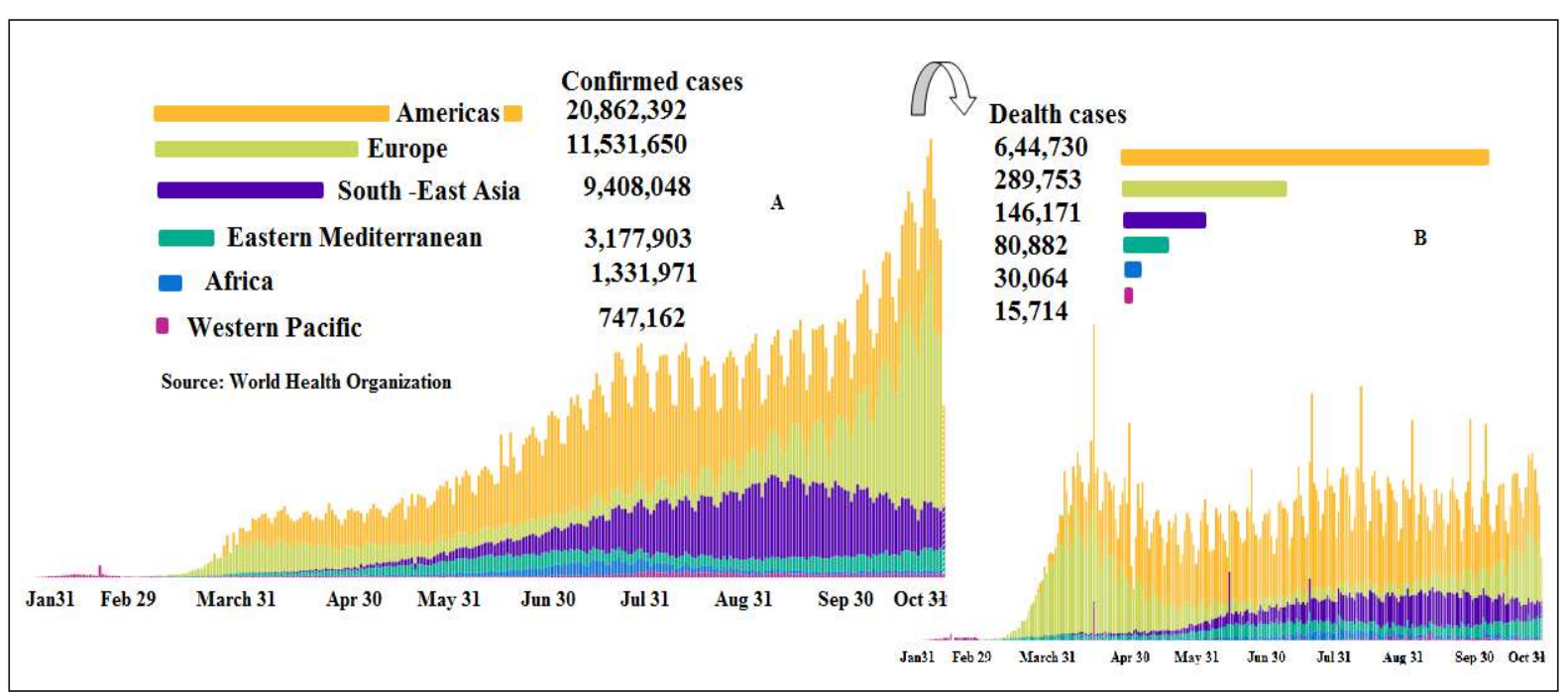

Figure 7: Epidemic Curve of confirmed COVID-19 by date of report [Source WHO, situation Report 28, Nov 2020].

\section{COVID-19 Crisis in India since $30^{\text {th }}$ January 2020} India, confirmed the first case of COVID-19 in Kerala on 30 January 2020 from person returning from Wuhan. Till then the outbreak pattern steadily increasing across the country. The outbreak of the novel coronavirus in India is currently in stage two, ie. local transmission and cluster cases. There have been no signs of community transmission( $3^{\text {rd }}$ stage) as per the Bulletin of Indian Council of Medical Research. In
India, from Jan 3 to 4 November 2020, there have been 8,313,876 confirmed cases of COVID-19 with 123,611 deaths.

There are 72 laboratories under ICMR that are functional and equipped to test of the novel coronavirus or COVID-19. Laboratories operated by other government departments and hospitals will soon be equipped.

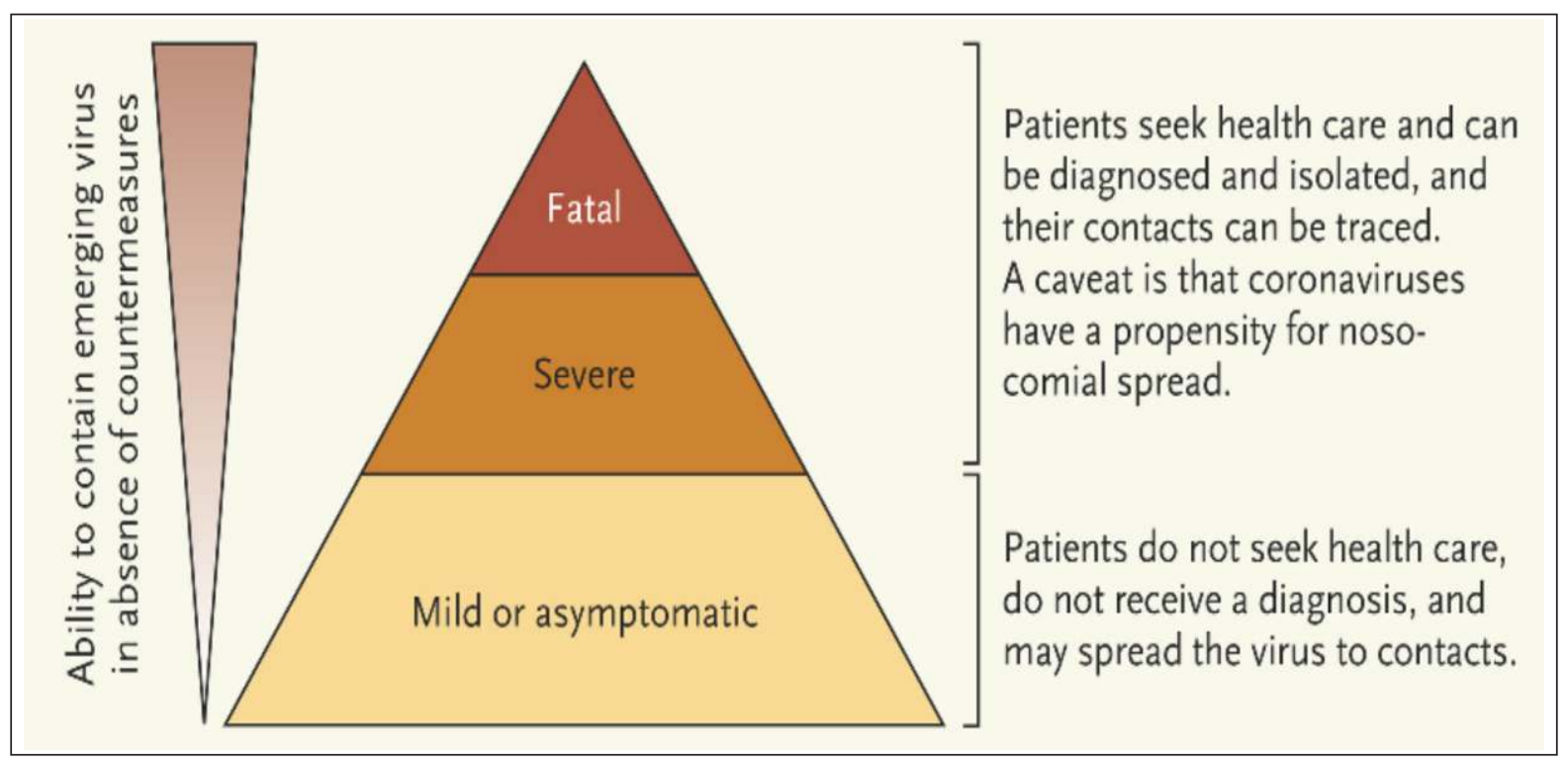

Figure 8: Surveillance Pyramid and its relation to the outbreak [10]. 
Pattern and comparison of a cumulative number of confirmed cases in India with selected countries after $100^{\text {th }}$ case indicate that in India around March the confirmed cases double in a week while China, South Korea, Japan it has already flat curve. Whereas in Italy, Spain, and Iran the confirmed cases double every after $2^{\text {nd }}$ and $3^{\text {rd }}$ day [Figure 6]. Health Bulletin released on the website of the Ministry of Health \& Family Welfare (MoHFW) on $28^{\text {th }}$ March 2020 confirm the total of 775 active COVID-19 cases and 19 deaths have been reported in 27 states/union territories and varied with time. The number of cured patients also varies depending on the status of person and stage of infection and at present 79 cases have been cured/discharged. Health Bulletin released on the website of the Ministry of Health \& Family Welfare (MoHFW) on $28^{\text {th }}$ March 2020 confirm the total of 775 active COVID-19 cases and 19 deaths have been reported in 27 states/union territories and varied with time as shown in Figure. The number of cured patients also varies depending on the status of the person and stage of infection and at present 79 cases have been cured/discharged.

In the current situation, the proportion of asymptomatic -mild cases versus severe -fatal cases is unknown for COVID-19 and this knowledge gap hampering the realistic evaluation of the virus, epidemic potential and complicates the outbreak response. In addition to the vulnerability of health care settings to outbreaks of emerging coronaviruses, hospital populations are at significantly increased risk for complications from the infection. Age and coexisting conditions like diabetes or heart disease are independent predictors of adverse outcome in SARSCoV and MERS-CoV. Thus the surveillance pyramid in Figure 7 indicates that emerging viruses that may go undetected because of a lack of severe disease in healthy people can pose a significant risk to vulnerable populations with underlying medical conditions [10]. We are expecting the alarming COVID-19 cases in the coming days due to the above.

\section{Surveillance and Testing}

International Air travel emerges as the key factor that initiated spread and accelerated the pandemic situation across the globe. Various surveillance procedures adopted depending on the epidemic stage and surveillance facility in hand that can be repurposed for COVID-19 surveillance work, and resources available to monitor, identify and measure impact on the population and the healthcare system and to measure the impact of any mitigation measures. In the present scenario, the Indian government concerned and asked the states /UTs to effectively monitor 15 lakh international air passengers who came from January to 23 March as there appeared to be a gap between the actual monitoring that "may seriously jeopardize the efforts to contain the spread of COVID19[The Hindu Newspaper, $27^{\text {th }}$ March]. Although the Indian Prime Minister announced a 21-day nationwide lockdown from 24 $4^{\text {th }}$ March(midnight), 2020, a complete ban is being imposed on people from stepping out of their homes to protect the vulnerable population.

In countries with local clusters of limited transmission, positive specimens should be subjected to verification by targeting the second gene of COVID-19 in an RTPCR assay. Whereas in areas with local community transmission detection of a single discriminatory target by RT-PCR is considered enough. Confirmatory testing should be done only for specimens where the first result is exactly not interpretable or the RT-PCR cycle threshold value is above 35 with repeated testing and confirmation is advised. For hospitalised patients and during specific outbreaks the serological assays performed by collecting serum specimens at symptom onset, or at admission and at the convalescent stage, or at discharge, will be useful for later seroepidemiological studies should be done [11].

\section{Role of the World Health Organization in the present scenario}

The WHO established a formal worldwide network called Global Alert and Response Network in 2001 to monitor and track such infectious disease outbreaks in every region of the world. After the outbreak of COVID-19 in central china on $2^{\text {nd }}$ January 2020, the three levels of WHO (China country office, Regional Office for the Western Pacific and headquarters) have been working together to respond to this outbreak. WHO has been assessing since outbreak around the clock and concerned both by its severity, alarming levels of spread and inaction. Finally WHO enforced to declare the outbreak as a Public Health Emergency of International Concern (PHEIC) on 30 January 2020. In the present scenario the WHO made the assessment and characterized the COVID-19 as a pandemic on 11 
March 2020 and till then are bringing together resources from across the organization to deliver the following:

- Increasing understanding of the disease by constantly analysing data as we receive it and working closely with global experts on a range of topics. WHO is proposing specific studies to better understand transmission, risk factors, and the source of the infection.

- Communicating with the public on how to protect themselves and others, especially the vulnerable and those at the highest risk.

- Keeping countries and the general public informed by providing updated information through the International Health Regulations (2005), daily situation reports and dashboards displaying realtime data.

- Coordinating with WHO partners including other UN and development agencies, Emergency Medical Teams, the Global Outbreak Alert and Response Network (GOARN) and donor agencies.

- WHO helping countries to prepare for the rapid detection and response to cases, clusters and community transmission including sending supplies, providing technical expertise and training [7]

- WHO launches global mega trial of the four most promising coronavirus treatments

The basic principles as per the WHO to trim down the general risk of transmission of COVID -19 include the following:

- Avoid close contact with patients suffering from acute pulmonary infections.

- Frequent/regular hand-washing, especially after direct contact with ill people or their environment.

- Unprotected contact should avoid with farm or wild animals.

- Patients with symptoms of acute pulmonary infection should practice cough etiquette (Social maintain distancing, use cover, disposable tissues or clothing, and wash hands).

- Enhance standard infection prevention and control practices in hospitals, especially in emergency departments.

- WHO does not advocate any specific health measures for travelers. In case of symptoms suggestive of respiratory illness either during or after travel, seek medical attention and share their travel history with their healthcare provider [10]
Global challenges and impact of COVID-19

COVID -19 pandemic is an uncertain event and its full impact will partly depend on when an antidote can be developed and how effective towards control and prevention measures. There is a broad consensus that current pandemic acceleration will have a bigger impact on the economy than the spread of Severe Acute Respiratory Syndrome (SARS) in 2003.

\section{Challenges at research level}

COVID- 19 has emerged as a central paradigm in both medical science and research. Although the virus is not new to the science community, outbreak prompted an explosion of research including the structure of the virus; how it spreads in different communities; clinical features of the disease; potential drug targets; how effective quarantine measures are; and the psychological effects of the outbreak on health workers. More than 900 papers, preliminary reports and preprints related to coronavirus have been published since its outbreak around the globe [Figure 9]. The challenges posed by the coronavirus are broad-ranging: from early detection, containment, and isolation, to mitigation and segmentation, and eventually to the end of the disease. The coronavirus virus usually undergoes random mutation and altering the DNA sequences so frequently that the mutants are in no way similar to that of its wild type. The resultant mutants have the novel capacity of invading and infecting and have high mutational rates. No new/existing drug or vaccine can be effectively administered without knowing the entire genome sequence of COVID- 19.

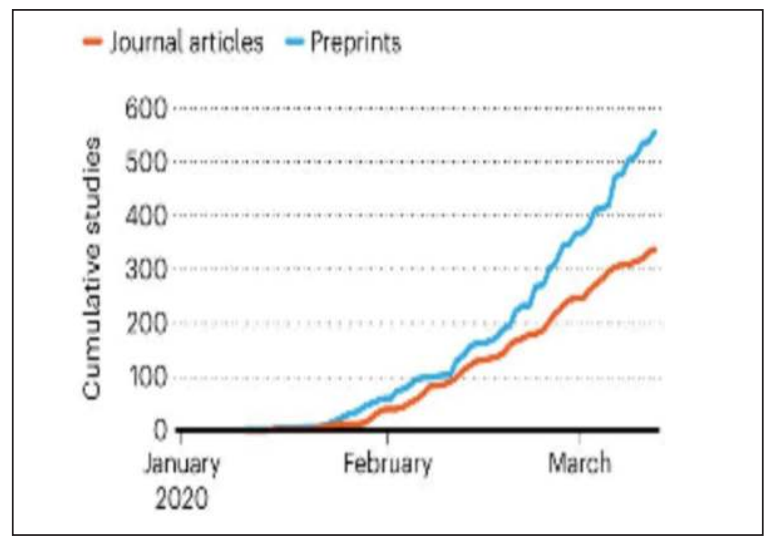

Fig. 9: Coronavirus related research publication across the globe since the outbreak. 
WHO announced a large global trial, called SOLIDARITY on $27^{\text {th }}$ March, 2020 to find out whether any can treat infections with the new coronavirus. It's an unprecedented move that leads to an all-out, coordinated push to collect robust scientific data rapidly during a pandemic. Scientists have suggested numbers of existing compounds for testing, but WHO is focusing the four most promising therapies: an experimental antiviral compound called remdesivir; the malaria medications chloroquine and hydroxychloroquine; a combination of two HIV drugs, lopinavir, and ritonavir; and that same combination plus interferon-beta, an immune system messenger that can help cripple viruses. Some data on their use in COVID-19 patients have already emerged the HIV combo failed in a small study in China-but WHO believes a large trial with a greater variety of patients is warranted[15].

\section{Challenges at control me sure level}

The COVID-19 has developed at such an alarming rate that many countries have already declared a state of health emergency, with those worst hit declaring lockdowns to avert further spread [13, 14]. Fatality rate of COVID-19 is 10 times more while the spread rate is comparatively double to that of seasonal flu. Therefore, there is an urgent need for accurate and well-timed laboratory testing of specimens from cases under examination is a critical part of the management of COVID-19 and emerging infections in general. However, chronic shortage of laboratory diagnostic facility at the national or local level will impede the epidemic response. In the current scenario, it has been seen that the health services are worst hit and exposed across the globe even for developed nations like Italy, Spain and U.K and the USA, etc. Asymptomatic carriers, shortage of test kits and COVID-19 as a new pathogen complicate efforts in trying to contain the transmission. The increased infection cases inevitably crush the health system as doctors and nurses are overworked to carry on with new cases, as well as the number of hospital facilities especially intensive care units (ICU).

A chronic global shortage of personal protective equipment (PPE) has been matter of concern and highlighted by WHO in WHO COVID-19 Situation Report -68, 28 March 2020 which is one of the most urgent threats to our collective capacity to save lives. Although WHO has already shipped nearly 2 million
PPE items to 74 countries and is preparing to send a similar amount to a further 60 countries.

\section{Challenges and impact at Economic level}

Pandemic acceleration of COVID-19 formulated the significant adverse consequences in the global economy including the direct disruption to global supply chains, weaker demand for services and imported goods, and the wider regional declines in international tourism and business travel. Risk aversion has increased in financial markets, interest rate falling to a record low and business and consumer confidence have turned down. As the OECD Interim Economic Assessment on Coronavirus (Figure 10) that annual global

The Covid-19 pandemic is unprecedented in its global reach and impact, posing formidable challenges to policymakers and to the empirical analysis of its direct and indirect effects within the interconnected global economy.

The Covid-19 pandemic is a global shock 'like no other', involving simultaneous disruptions to both supply and demand in an interconnected world economy. On the supply side, infections reduce labour supply and productivity, while lockdowns, business closures, and social distancing also cause supply disruptions. On the demand side, layoffs and the loss of income (from morbidity, quarantines, and unemployment) and worsened economic prospects reduce household consumption and firms' investment. The extreme uncertainty about the path, duration, magnitude, and impact of the pandemic could pose a vicious cycle of dampening business and consumer confidence and tightening financial conditions, which could lead to job losses and investment. Key challenges for any empirical economic analysis of Covid-19 are how to identify this unprecedented shock, how to account for its non-linear effects, how to consider its cross-country spillovers (and other observed and unobserved global factors), and how to quantify the uncertainty surrounding forecasts, given its unprecedented nature.

A rapidly growing body of research investigates the heterogeneous, non-linear, and uncertain macroeconomic effects of Covid-19 across countries, sectors in individual countries, as well as on a global scale. 
GDP growth is projected to drop to $2.4 \%$ in 2020 as a whole, from already weak $2.9 \%$ in 2019 , with growth possibly even being negative in the first quarter of 2020. Global growth expected to drop to $1 \frac{1}{2}$ percent in 2020 , half the rate projected prior to the virus outbreak [15]. Therefore IMF already announced and stands ready to support vulnerable countries with different lending facilities, including through rapid-disbursing emergency financing, which could amount up to $\$ 50$ billion for low-income and emerging markets. Of this, $\$ 10$ billion is available at zero interest for the poorest members through the Rapid Credit Facility [16].

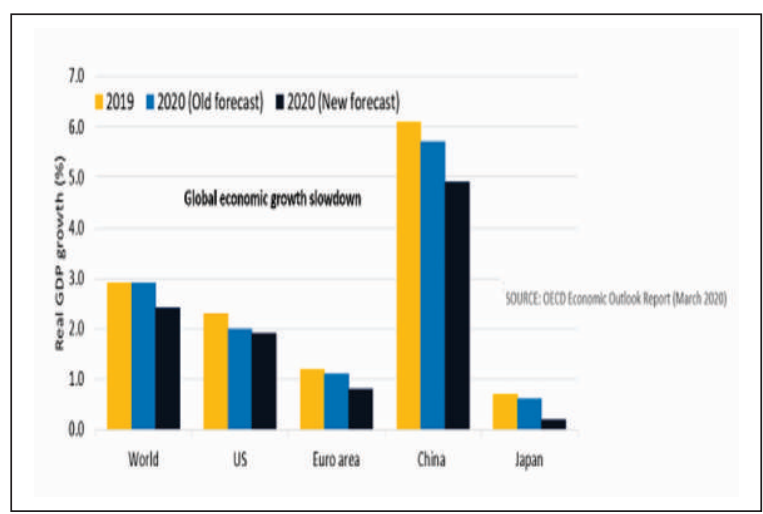

Figure 10: Comparative global economic growth in the post and pre COVID-19 crisis.

\section{Impact at Environmental level}

Although the global efforts to control the outbreak seem to have curbed energy consumption and air pollution. Harsh lockdown is catalyzing system changes that can be sustained beyond the Corona crisis around many countries. Satellite data collected by NASA and the European Space Agency show a sharp reduction in atmospheric nitrogen dioxide which is produced during fossil fuel combustion [17]. There is another hidden concern of COVID-19 since its outbreak is its possible use as biological warfare weapons like anthrax powder.

In the present scenario the credible communication of the critical risk, event information and counter misinformation should be disseminated to all communities. And concern institutions must work together to minimize social and economic impact through multispectral partnerships.

\section{Summary}

COVID-19 is spreading stealthily across the world since its outbreak. At the same time, some Asian countries like Japan and South Korea have been reporting a slowdown in the growth of COVID-19 cases due to the concept of "Testing is central" to outbreak response that leads to early detection to minimizes further spread. The full spectrum of Covid19 ranges from mild, self-limiting respiratory tract illness to severe progressive pneumonia, multiorgan failure, and death. Asymptomatic carriers, scarcity of test kits and COVID-19 as a new pathogen complicate efforts in trying to contain the transmission and can pose a significant risk to vulnerable populations with underlying medical conditions. Also, the proportion of mild, asymptomatic cases versus fatal cases is currently unknown for COVID19 and this knowledge gap hampers the realistic assessment of virus epidemic potential and complicates the outbreak response. Therefore the challenges posed by the coronavirus are wide-ranging: from early detection, containment, and isolation, mitigation, and segmentation, and ultimately to the end of the disease. Around the world, measures have been speeding up to contain the global spread of COVID-19 by border control measures, such as airport screening and travel restrictions and declared a state of emergency, with those hardest hit declaring lockdowns besides quarantine measures. Governments all over the globe must direct their states to effectively monitor millions of international and domestic air passengers travelled from January to March as there appeared to be a gap between the actual monitoring that "may seriously jeopardize the efforts to contain the spread. We all are optimistic that medical science and research should timely get into the insights, answers, and recommendations to handle and address the COVID-19 pandemic which has already brought considerable human suffering and major economic disruption. Although WHO has already announced its large global trial, called SOLIDARITY for effective and timely tacking of COVID-19. The exact global impact and extension of this new pandemic acceleration are yet uncertain. However, the global respiratory illness crisis can be most plausibly managed by preparing for the worst and hoping for the best.

\section{REFERENCES}

1. Tyrrel, D. A. J., J. D. Almedia, D. M. Berry, C. H. Cunningham, D. Hamre, M. S. Hofstad, L. Malluci, and K. McIntosh. Coronavirus. Nature 1968; 220, 650.

2. Masters PS. The molecular biology of coronaviruses. Advances in Virus Research 2006; 66: 193-292. 
3. Enjuanes L, Gorbalenya A.E, de Groot R.J, Nidovirales. In Encyclopedia of Virology, 3rd Edn, Mahy B..WJ, Van Regenmortel MHV Elsevier: Oxford, 2008; 419-430.

4. Adams MJ, Carstens E.B. Ratification vote on taxonomic proposals to the International Committee on Taxonomy of Viruses. Archives of Virology 2012; 157(7): 1411-1422.

5. National Institute of Infectious Diseases, Japan. Field Briefing: Diamond Princess COVID-19 Cases, 20 Feb Update 2020 [March 10, 2020]. Available from: https://www.niid.go.jp/ niid/en/2019-ncov-e/9417-covid-dp-fe-02.htm

6. https://www.ecdc.europa.eu/sites/ default/files/ documents/RRA-sixth-update-Outbreak-ofnovel-coronavirus-disease-2019-COVID-19.pdf.

7. World Health Organization (WHO). Report of the WHO-China Joint Mission on Coronavirus Disease 2019 (COVID-19) 2020 [cited 20201 March]. Available from: https://www.who.int /docs/default-source/coronaviruse/who-chinajointmission-on-covid-19-final-report.pdf.

8. Tseng CT, Tseng J, Perrone L, Worthy M, Popov V, Peters C.J. Apical entry and release of severe acute respiratory syndrome-associated coronavirus in polarized Calu-3 lung epithelial cells. Journal of Virology 2005; 79(15): 94709479.

9. Ewen Callaway, David Cyranoski, Smriti Mallapaty, and Jeff Tollefson, The coronavirus pandemic in five powerful charts. Nature 2020; 579, 482-483.

10. World Health Organization. Infection prevention and control of epidemic-and pandemic prone acute respiratory infections in health care. WHO guidelines 2014 [17 January2020].
Available from:https://www.who.int/ csr/bioriskreduction/infection_control/publicatio n/en/.

11. World Health Organization (WHO). Laboratory testing for coronavirus disease 2019 (COVID-19) in suspected human cases: Interim guidance - 2 March 2020: WHO; 2020 [11 March, 2020]. Available from: https://www.who.int/ publications-detail/laboratory-testing-for-2019novel-coronavirus-in-suspected-human-cases.

12. Vincent J. M. A Vincent J. Munster, Marion Koopmans, D.V.M., Neeltje van Doremalen, , Debby van Riel and Emmie de Wit. Novel Coronavirus Emerging in China - Key Questions for Impact Assessment. New England Journal of Medicine, 2020; 382:692-694.

13. He, R., F. Dobie, M. Ballantine, A. Leeson, Y. Li, N. Bastien, T. Cutts, A. Andonov, J. Cao, T. F. Booth, F. A. Plummer, S. Tyler, L. Baker, and $\mathbf{X}$. Li. Analysis of multimerization of the SARS coronavirus nucleocapsid protein. Biochemical and Biophysical Research Communications 2004; 316:476-483.

14. https://www.sciencemag.org/news/2020/ 03/who-launches-global-megatrial-four-mostpromising-coronavirus-treatment.

15. https://www.euromoney.com/ article/ b 1 kcz 3 f6dpfh $1 \mathrm{y} / \mathrm{special-risk-survey-}$ coronavirus-dampens-enthusiasm-forchina?copyrightInfo=true

16. OECD Interim Economic Assessment Coronavirus: The world economy at risk 2 March, 2020.

17. https://www.nature.com/articles/d41586-02000758-2 